\title{
Relational Intuition and Suggested Indicators for Developing Mediator Capacity
}

\section{Delma Sweeney}

\begin{abstract}
This article presents findings from a study of mediators' experience of intuition in practice, a subject not previously researched. A qualitative phenomenological study gathered data from senior Irish mediator respondents in focus groups, from individual interviews and from mediator journals about their experiences of intuition in practice. The research finding shows that the development, cueing, and arrival of a mediator's intuition is a holistic process, a mind, body, emotional and spiritual experience. This study suggests that the inclusion of these aspects of self in training has the potential to increase mediator intuitive capacity.
\end{abstract}

\section{Keywords}

Mediator, mediation, relational intuition, suggested indicators

\section{Introduction}

Lang and Taylor (2000) provide a theoretical and methodological process for ongoing mediator development and learning, however the progression and growth of mediator competence and ability is a little researched subject. Leiberman, Foux- Levy and Segel (2005) write that "regardless of the extensive literature focusing on standards for mediator development, empirical research does not refer to the development and training that transforms a mediator from a 'novice' to 'expert' and has yet to define what constitutes adequate professional training in the advanced stages" (Leiberman, Foux-Levy and Segel, 2005: 239).

Intuition has been found to be one of the main capacities of artistic masterful practice in many professional disciplines (Dreyfus \& Dreyfus, 1986, Benner, 2001). A study of how mediators develop their intuitive practice, how they experience and use their intuition has the potential to uncover some of the indicators for mediator development, signalling content for teaching programmes in the field.

A number of mediation writers include the experience of intuition in mediation practice in their work (Benjamin, 2001, Lang \& Taylor, 2000, Cloke, 2001, LeBaron, 2002, Lederach, 2005, Rooney, 2007, Rooney \& Ross, 2013, Mason et al, 2013), however intuition in mediation has not been researched previously. In addition, relational intuition has received sparse research attention (Sinclair,2011). 


\section{The Study}

Phenomenological and Gestalt paradigms and methodology provided the orientation and process for the research engagement with the mediator respondents in this study. The object of the phenomenological paradigm is "to inductively and holistically understand buman experience in context-specific settings" (Patton: 1990: 37). Yontef (1979b) defined Gestalt therapy as clinical phenomenology. Phenomenology, like Gestalt therapy, focuses on immediate experience with the belief that "the person can only be understood in terms of an intentional relationship with the world (place) and that experience is physical, (body) in a temporal frame of reference (time)" (Clarkson: 2004: 16). A group of twenty-eight practitioner workplace and family mediator's self-selected in response to an invitation to join the research study. [Practitioner mediators are experienced in practice and have completed a number of requirements to be accredited by the Mediators Institute of Ireland (www.themii.ie, 2011)). This request to participate in the research was sent to the thirty-four practitioner mediators listed for the Leinster province on the Mediators Institute of Ireland website (www.themii.ie). Methodological triangulation was achieved through the data collection methods of focus groups, individual interviews and mediation intuition journals. The multiple method enhanced the credibility of the research findings. The approach of asking participants to reflect on a mediation process soon after a session fits with Kressel's (1997) description of reflective research. He holds that reflective practice and reflective research can strengthen mediation theory by studying subjects germane to mediation practice. Units of general meaning and clustered themes were drawn from the transcribed texts of these three data collection methods. This process facilitated the gathering of findings from the mediators' rich descriptions of their experiences of intuition in mediation practice.

\section{What is Intuition?}

Arvidson (1997) presents intuition in the context of how we pay attention to the continuous stream of life as it passes us by. He presents the paradigm of the "sphere of attention" (2010: 10), as the context for this experience. The focus of attention or theme is the centre of this sphere, where we concentrate our attention from moment to moment. Capacity is developed in a professional domain through building knowledge and practice arising from the accumulated instances of the focus of attention. These experiences and the awareness they generate are banked in long term memory and stored in patterns. Intuitions happen when one or more of these memories are cued by and synthesised with an experience in the present. This synthesis creates an attentional shift, a new understanding, an intuition. 


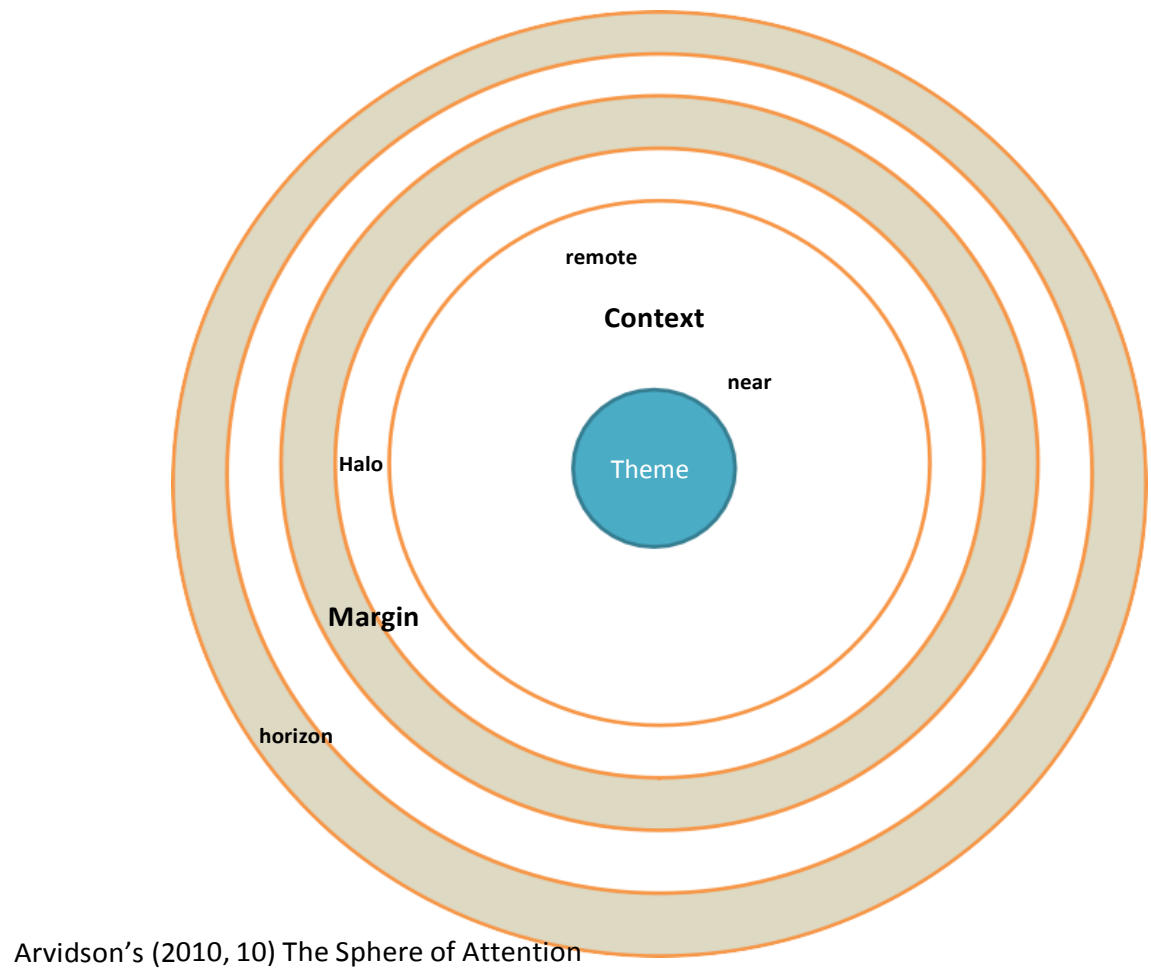

The experience of intuition in practice was reflected in a variety of ways by the mediator respondents, which included their mind, body, spirit and emotions. The mediators describe how their whole self is involved in an intuitive process, from the time they pay attention to a particular aspect of the mediation, or their own reactions, client or clients' dynamic, to the arrival of an intuition as a thought, a physical sensation, a spiritual or emotional response or a combination of these.

While Arvidson's (1997) paradigm gives clarity to the process of intuition creation as a theory, the mediator respondents' descriptions of relational intuition in practice contribute to and change this paradigm. The work of Perls (1969) and Staemmler (2011) also add to the understanding of the nature of relational intuition in mediation.

\section{Mediators' Experience of Intuition in Practice}

The mediators in the study describe a process in the development and arrival of intuition as follows:

I. The Development of a Memory Bank of Mediation Knowledge and Experience

II. The Cueing of an Intuition

III. The Arrival of an Intuition

\section{The Development of a Memory Bank of Mediation Knowledge and Experience (Building capacity in a particular domain through experience and practice)}

Mediator respondents reported an increase in their use of intuition that corresponded with additional mediation experience. Niall says that, with many years of practice, it was not until recent years 
that he became aware of his intuition which "... comes when you are becoming more at ease with yourself and more relaxed in the room". Alice states that intuition comes with “...the skill and the knowledge that you have, over time and with mediation experience and training".

Writers in the field of intuition concur that expertise develops with practice. This understanding is confirmed by Bastick's (1982) meta-analysis of the intuition literature, which lead him to include "influenced by experience" (1982: 25) as a characteristic of intuition. Mediation practice is one of the factors laid down in the unconscious over time that builds a mediator's capacity for intuition. The development of a memory store of mediation knowledge and expertise from which intuitions are cued, begins when the student takes a mediation programme and integrates previous personal and professional experience with what is taught on the course. In a focus group discussion George highlighted the importance of mediation training developing "self-awareness, awareness of others, how to connect" in the student. He goes on to say that intuition, mediation training and practice experience are "very deeply" related. He and others in a focus group agree that the goal of developing self-awareness is highly relevant to increased intuitive capacity.

Cahill illustrates her development from the time she began mediation practice. At that time, she projected feelings onto clients: “... if they were talking about a drama I'd have it as a double drama." If they said, 'I can't afford the money....... I'd be heartbroken for them."... "I began to get really confused. I was thinking, "my goodness, whose stuff is this?" Then through experience, reflection, writing down her experiences and working with her supervisor she says that "I started to work it out...it was there, the space between us, and it remained there...and that was it. I didn't take on their upset and that's how I managed it really." Now, after four year of practice she is clear about what she is feeling and what clients are feeling. She can discern that some of the emotions she is experiencing are client's emotions and this gives her information for her mediation work. Beginning mediators especially need to be alert to transference or attribution. The review of mediation sessions, especially in supervision, facilitates a deepening of a mediator's understanding of interpersonal dynamics and what they may be projecting onto clients. Supervision enables the practitioner examine what they are bringing to the session and how they are influenced by theirclients.

Laurence reflects that in his profession of origin he would have thought that, "I was good at listening to people and looking at body language. But I believe that since I started to do mediation I've tended to be more conscious of people, the way they carry themselves, the way they talk and what they are saying and what they are not saying." Mediators in the study demonstrated awareness of others in their discussions and illustrations and also described their own physical and emotional reactions as they practiced. They reported an inner dialogue about their reflections. The mediators sensed connection or lack of connection to the mediation participants. These are some of the experiences that mediators reflect on and refine over years of practice and "store away, out of consciousness" (Nelly), banked in their unconscious long term memory. The location for the store of this banked experience from which an intuition is cued has been variously described in the literature as the unconscious, (Jung, 1923, Reik, 1948, Poincare, 1964, Assagioli, 1965, Perls, 1969), the 
preconscious (Bastic, 1982), and the horizon of consciousness, (Arvidson, 1997).

Boud et al (1985) write that practice development does not arise from theoretical knowledge and experience alone. Learning from experience is enhanced by structured reflection. They hold that reflective activities have three stages in practice based learning, preparation, engagement and processing. In this study mediators describe how they prepare for mediation, engage in practice, reflect on practice during the session and review the session at a later time. Renee, a mediator for ten years, describes how she prepares for and reflects on her practice..." I would do a reasonable amount of, I suppose, hypothesis kind of consideration prior to going in to situations to meet with people. And between pre-mediation and mediation I will.... reflect on the various kind of possibilities or hypotheses as they might exist." She goes on to describe in detail how she "downloads" and sleeps on what has happened in the mediation session. Renee thus illustrates how she processes her work so that what is then stored in long term memory or the unconscious is reflected on, examined and refined. For most mediators in the study, their intuitions inform their hypotheses. Mediators described how they test this out by evaluating the effects of interventions derived from their hypothesis. Others described how when they develop the mediation process based on their intuition and they find that their intuition is incorrect, they rely on their experience to be able to rectify what they have done or "catch the glass before it drops"(Fitz) to correct any intervention they have made based on their intuition.

Continued learning, reflection, supervision and coaching can refine what is laid down in patterns in this store. Hogarth (2001) adds to Dreyfus and Dreyfus (1986) understanding of intuition by highlighting that a person needs to have a broad basis of information to lay down "good theories" in longterm memory in order that their intuitions are reliable and grounded. He also holds that memories laid down in supportive environments in which the person has had good teaching and has reflected on the results of their work are more likely to generate accurate intuitions. This bank of mediation knowledge is cued by mediator's focus of attention in the present, delivering an intuition. These memory patterns, banked in long term memory are prompted by the same thought, bodily feeling, sense, emotion or spiritual sense as when the memory of these experiences were originally stored.

\section{The Cueing of an Intuition (a cue from the present sparking long term memory patterns and the arrival of an intuition)}

Con says that in his experience intuitions arise through "the synthesis of cues, straight away in that moment". This subliminal process is named by Bastick's as "parallel processing of cues" (1982: 9). The mediators in the study describe how intuitions are cued by the senses, a thought, an image, an emotion or a spiritual sense. Intuitions happen when a mediator is cued by a situation arising from the focus and context of their attention. This circumstance creates a synthesis between the present experience and patterns in the long term memory or unconscious, producing an intuition.

Cahill described how she meets people coming to mediation. She said "When a person walks into the room I sense things... I sense something about the way they shake hands, the way they 
look at you, the way they introduce themselves to you and it sends off...the senses, then sets off something in my gut." Cahill pays attention to the people she meets, absorbing everything about them through her senses. They are the focus of her attention; the context is the mediation process and the immediate physical surroundings. Cahill's unconscious, or in Arvidson's (1997) terms, material in the horizon of consciousness, is cued by what she experiences and she has a bodily reaction which she then translates as an intuition and recognises. In this manner Cahill gains information that contributes to her knowledge and understanding of individuals in mediation, of their conflict and of ways to connect and mediate with them. For example, Cahill gives an example of how a handshake cued an intuition through touch. She describes her meeting with a couple who were separating, saying that when she shook hands with the husband: "There was something about his handshake that didn't match with the ending of the marriage, you know, the end of the relationship, the end of a life together....it was a completely different feeling than somebody who's ending a relationship. If I could say anything his handshake was too firm." This example illustrates how her sense of touch cued her intuition, giving her information about this mediation participant. She says, I didn't ...judge, I just observed and $\boldsymbol{I}$ got that information. She adds that when you shake hands with mediation clients "Oh $\boldsymbol{m y}$ goodness!... you're shaking hands with all their ancestors."

In 1962 Perls famously said, "Lose your mind and come to your senses" (Shepard, 1975: 3), a statement that asks a person to stop analysing and connect with their body and emotions. This directive was intended to counteract the propensity for people to respond cognitively and analytically to all experiences. Perls held a holistic understanding of human nature based on the "inseparable unity of bodily, emotional and mental experience, upon the integrity of language, thought and behaviour", (Clarkson \& MacKewn, 1993, 35) believing that the body, mind and spirit function as a whole.

Mary described how she begins her work with people in mediation: "I can feel myself going straight into opening all my senses then and just allowing everything just to flood in so that I can try to figure out what is going on here. That's what I do. I allow everything in and I try quite quickly try to make sense of it."

Mary describes a mediation session just finished in which a husband participant was very depressed and disengaged. He was about to go to gaol. She said that his "energy was just very, very dead, very quiet" and "I have a sense of him closing in on himself do you know, looking in and not looking out..... He looked like there was darkness inside him. He looked eerily still, not calmly still do you know, but unhappily still like he was shutting down, like he was just systematically shutting himself down." As researcher I noticed that Mary pointed to her stomach and commented on this. Mary said, "Yeah I felt it there between my ribs, that this man is not here."This was a first session and she was concerned that if she did not engage him he would not come back to mediation. A further anxiety was that he was suicidal. She wanted to catch the meaning making of this man who was in a dark place. She searched for a way to connect with him and in doing so cued stored memory patterns relating to this challenge. Her intuition brought her the message that she should slow down and attune to this man. Mary then talks about "Not rushing on" as an element of her intuition. 
She says that "even though I'm feeling this anxiety" and that she goes down "a number of levels inside myself" to "be still." Then she reports "I could feel myself deliberately slowing down to synchronize with him... I felt like he was only barely there and that it was one of those fragile, very fragile raw moments that if I made the wrong move or if I moved to quickly or too bluntly towards him he would move away. So for me my anxiety was how am I going to synchronise with this man's energy, how am I going to stay beside him long enough to connect with him?" The thought then came to her; "He sees no future." She said to him: "So Jack, you're twenty-eight now. You're very young, a very young person to me, very young'. So I said; 'In five years' time, six years' time you'll be in your early thirties. If you spent the next five or six years in prison you're still in your early thirties when you come out of prison. I said, you've a long life ahead of you then and you have a child. So I said... what would be the best kind of outcome for you, for yourself and then what would be the best kind of outcome for your child ... when you are coming out of prison?' So that kind of made him sit up a bit, I could see." Jack's response to these questions was that he “came out of his daydream.... I think he hadn't got that far in his own head" and when he began to think about this he also reluctantly started to connect to life and to engage in mediation. Schon (1995) describes how the practitioner tests their "knowing in action" by running "an on- the-spot experiment whose results he interprets, in turn, as a "solution," an outcome on the whole satisfactory, or else as a new surprise that calls for a new round of reflection and experiment." This is "a way of looking at problem-setting and intuitive artistry that presents these activities as describable and as susceptible to a kind of rigor that falls outside the boundaries of technical rationality" (Schon, 1995). If this man did not respond to Mary's question she would get this feedback from him, review her hypothesis depending on how he reacted and make a further intervention.

A cue, which can be a thought, a sensation, an emotion or a spiritual sense from the current focus of attention of the practitioner, sparks one or more patterns laid down in the mediator's unconscious long term memory. In this instance Jack was Mary's focus of attention and the combination of all that she took in through her senses about him and her search for a methodology to attune to him, cued and synthesised with patterns of relevant stored memory creating an intuitive response.

\section{The Arrival of an Intuition}

Mediators gave examples of "Aha" moments, when an intuition arrives with a sense of clarity and sureness. These intuitions can arise during the mediation session or afterwards. Sarah gave the example of this form of intuition at a time when she was reflecting on a mediation session in which the wife was "very aggressive and shouting." This wife says about her husband... “He's this. He's that. He's the other." Shortly afterwards Sarah was in church and in a reflective mood when she heard something the cleric holding that morning's service said. "And like that (clicks fingers) I thought that's the missing bit. ...That's it. And I (claps hands) got it. It was almost like that jigsaw piece went (makes noise), fitted in. Now the action in me was all down here." (She makes a noise 'shussss' and 
points to her solar plexus) ... It was almost like a coming of age in me, that I'd 'got it' about her...And when I think of her now in the aggression, the shouting, all of that around him, I think there is a tiny little person underneath all that, wanting to be able to say 'You let me down.' ...But there's nothing about her that would make you think she ever needed anybody." Sarah had been mulling over the session in the background of her mind and the cue provided by the cleric synthesised with her knowledge of marital separation and of her experience of this wife in mediation to produce an intuition.

When reviewing another mediation session in which a young woman was harassed Sarah describes her intuition as having a sense of fear in her own body, the sense experienced by the mediation participant. Sarah said, "I certainly felt the feeling she was feeling, ...it's like contagion isn't it, you actually feel... what they're feeling. And then of course you have to test that out afterwards." Mediator respondents in the study regularly report experiencing the same emotion as a client both physically and emotionally. A number of instances are also given when the mediator felt nauseous as a result of an unexpressed emotion.

Gendlin (2004) writes, “.... we don't just have interactions; we are interaction with the environment, - other people, the world, the universe, and we can sense ourselves as such" (2004). Mediators' Intuitions arrive through the mediator's mind, body, spirit or emotions, through a thought, an image, metaphor, a felt sense or an emotional or spiritual reaction. Bill said, "after a couple of hours with each side...you pick up a real sense of ...who they are, what they're like...I think you make that assessment based on experience probably more than anything else. But I also do it on feeling...it's how I feel people are. I suppose you could say my sense of what's here, who am I dealing with."

Intuitions enable a creative mediation process in which the mediator brings all that they are to the session, in interaction with all that the mediation participants bring to the process to create a unique interactive event. Angelina said "How would I describe intuition? Intuition is knowing...it's knowing that you're connected, that you're in relation with somebody." When engaging in empathic listening, the speed of processes defies a listener's ability to have time to create theories of the other, according to Staemmler (2012). As a consequence, people rely on "intuitive, embodies processes" (2012: 10). He uses the term "encorporation" $(2012,11)$ to describe this process. Niall described his interaction with mediation participants as intuitive when he describes the following, "you're following each moment as they talk and... you are imagining with them. But you have to check it out. So that whatever she might be saying ...I can see how that affected the other person. I'm looking across at her eyes, to see if she is picking it up, or how is she picking it up." In addition to naming this practice as intuitive, Niall calls this mediation work, "compassionate witnessing". The inter-subjective field is described as a spiritual connection by a number of mediators. The Daliai Lama explains that "if we are genuinely able to feel empathy for others, then compassion is the natural outcome" (Davis, 2010, 3). In the mediation relationship, inter-subjective dialogue has a two-person consciousness/unconsciousness from which meaning is created, from which individual inner meanings are influenced by "the other" and translated culturally into outer expression of meaning in a cycle of engagement with others in a shared 
and communal world. The experience of compassion for others is followed by a sense of unity with all humankind, nature and the environment, a sense of nonduality. And in this sense "a borizon opens up that transcends the individual, and this allows the subject to bave the experience of being connected to all that surrounds her" (Staemmler, 2012: 234). This extension of horizon expands ever outwards from Arvidson's (1997) concentric circles in the sphere of attention, as the person recognises the systemic connection between everything in the universe.

\section{Discussion \& Implications for Practice}

The mediator respondents believe that training is an important starting point for the development of intuitions. Learning in the specific domain of mediation usually begins with deliberative learning which is taught through the presentation of explicit understandings of knowledge. Mediation programmes generally also include significant role play, consisting of simulations of conflicts in which the student plays a role of conflict participant or mediator. However, the time taken to deliver mediation courses, 16 to 40 hours, (Wissler, 2002, Kressel, 2013) provides limited opportunity to focus on the student's awareness of their mind, body, spirit, and emotions as they practice mediation. Having a chance to do so would inform their understanding that such awareness is important for their ongoing development. In Arvidson's (1997) terms, training engages what is stored in a mediator's memory bank firstly by what theory skills and practices the mediator learns. Our attention is influenced by our intention which means that what we have learned will affect what our senses absorb. We create meaning out of what we have learned. Paradigms that we have absorbed through courses, reading, workshops, experience in practice, coaching, supervision and our own reflections guide us but also influence our focus and attention. We ignore what is deemed not to have meaning. This then affects what is stored in the unconscious through the process of filtering and storing only that which has meaning and filtering out that which we infer has no meaning.

This study suggests that mediation programmes can be enhanced for the student by the addition of self-awareness and reflection, seeding processes for a beginning mediator so they include their whole selves as they progress in their learning. Beyond the classroom, reflective processes where personal experiences are examined in a holistic fashion result in "good theories" which are laid down in long term memory (Hogarth, 2011). Coaching, reflection, supervision and mindfulness practice (Winbolt, 2013) can fulfil this role for the mediator, deepening and enhancing the creation of meaning and expanding the multiplicity of cues that prompt intuition. The mediator then stores rich refined and complex memories in their long term memory or unconscious, deepening their mediation knowledge and capacity for intuition.

Note: All names have been changed and content amended to provide anonymity to the mediator respondents who took part in the research and their clients.] 


\section{Conclusion}

Winbolt, (2013) writes,

Mediation is founded upon a dynamic set of professional skills, as such we can learn, develop and maintain the habits of practice which distinguish us as conflict resolvers. As any profession evolves, outdated habits and practices can be discarded in favour of ideas which prove to be more effective.... It has moved on from the original prescriptive models to become more facilitative - less concerned about process and more aware of buman potential - than was once the case.

In this study the mediator respondents had moved on in their practice, paying attention to themselves as well as the mediation participants, testing out intuitive thoughts, sensations, physical reactions, emotions, images, metaphors and spiritual connections, deepening and enhancing their work in a feedback loop that lays down "good theories" in their stored memories. This finding suggests that the inclusion of self-awareness in mediation programmes and the ongoing practice of holistic reflection in conflict intervention work nourishes intuitive capacities in mediators and increases their learning as they practice. Note: Quotes from the literature are presented in italics in this article. Quotes from the mediator respondents are presented in italics and in bold.] 


\section{References}

Arvidson, P. S. (1996). 'Towards a phenomenology of attention.' Human Studies, 19, 71- 84.

Arvidson,P. S. (1997). 'Looking Intuit.' Chapter in Intuition: The Inside Story, editors

P.S.Arvidson \& Davis-R. Floyd (ed.) New York: Routledge pp.39-57.

Arvidson, P. S. (2010). 'Attention in Context.' Chapter in Handbook of Phenomenology and Cognitive Science, editors D. Schmicking and S. Gallagher, Springer, 2010, pp. 99-121.

Assagioli, R. (1965). Psychosynthesis, Wellingborough, Turnstone Press.

Bastick, T. (1982). Intuition: How We Think and Act. Chichester, New York, John Wiley \& Sons Inc.

Benjamin, R. (2001). 'Gut Instinct: A Mediator Prepares.' Family Mediation News,

Newsletter of the Family Section of the Association for Conflict Resolution. Summer, 2001

Benner, P. (2001). From Novice to Expert: Excellence \& Power in Clinical Practice, New Jersey, Prentice Hall.

Boud, D., Keogh, R. \& Walker, D. (1985)). Reflection: Turning Experience into Learning,

London, Kogan Page.

Clarkson, P. Mackewen, J. (1993). Fritz Perls, London, Sage.

Clarkson, P. (2004). Gestalt Counselling in Action, London, Sage Publications Ltd.

Cloke, K. (2001). Mediating Dangerously: The Frontiers of Conflict Resolution, San Francisco, Jossey-Bass.

Davis, J. L. (2010). The Dalai Lama's advice on depression. http://www.webmd.com/

depression/features/the-dalai-lama-and-depression-treatment. Downloaded 5/10 /13.

Dreyfus, H., \& Dreyfus, S., (1986), Putting Computers in Their Place. Social Research

(Spring 1986), 53(1): 57

Gendlin, E. (2004a). 'Thinking at the edge.' The Folio, 19.

Gendlin, E. T. (2004b). 'Introduction to thinking at the edge.' The Folio, 19.

Hayes, S. (2002). Family Mediators in the UK: A survey of practice. Family Law, 32, 760- 764.

Hogarth, R. M. 2001. Educating Intuition, Chicago, The University of Chicago Press.

Jung, C. G. (1923). Psychological Types or the Psychology of Individuation, New York, Harcourt Brace.

Kressel, K. (1997). 'Practice-Relevant Research in Mediation: Toward a Reflective Research Paradigm.'

Negotiation Journal, 13, 143-160.

Kressel, K. (2006). Mediation Revisited. In: DEUTSCH, M. \& COLEMAN, P. (eds.) The Handbook of Constructive Conflict Resolution: Theory and practice. San Francisco: Jossey Bass.

Kressel, K. (2013). 'How do mediators decide what to do? Implicit schemas of practice and mediator decision making.' Obio State Journal on Dispute Resolution, 709.

Kressel, K., Henderson, T., Reich, W., Cohen, C., (2012). 'Multidimensional Analysis of Conflict Mediator Style', Conflict Resolution Quarterly, vol. 30, no. 2, Winter 2012.

Kressel, K. \& Pruitt, D., (1989). Mediation Research: the process and effectiveness of third party intervention, San Francisco, Jossey Bass.

Lang, M., \& Taylor, A., (2000). The Making of a Mediator: Developing Artistry in Practice,

San Francisco, Jossey-Bass. 
LeBaron, M. (2002). Bridging Troubled Waters: Conflict Resolution From The Heart, San Francisco, Jossey-Bass. Lieberman, E., Foux-Levy, Y., \& Segal, P., (2005), 'Beyond basic training: A model for developing mediator competence', Conflict Resolution Quarterly, Volume 23, Issue 2, pages 237-257, Winter 2005.

Mason, S., Nan, S. \& Van De Loe, V. (2013). 'Dancing through Conflict: Developing Intuition for Mediation. 'In: LeBaron, M., Macleod, C. \& Floyer, A. (eds.) The Choreography of Resolution. Chicago: ABA Publishing.

Mediators Institute of Irealand. (2010). http://www.themii.ie. Accessed $19^{\text {th }}$ June 2010. Perls, F. (1969a). Gestalt Theapy Verbatim, New York, Bantam.

Poincare, H. (1929). 'Intuition and logic in mathematics.' Mathematics Teacher 62(3): 205-12.

Reik, T. (1948). Listening with the Third Ear: The inner experience of a psychoanalyst.

New York: Grove Press.

Rooney, G. (2007). 'The Use of Intuition in Mediation', Conflict Resolution Quarterly, vol. 25, no. 2, Winter 2007

Rooney, G. \& Ross, M. (2012). 'Shifting the Focus from Mediation the Problem to Mediating the Moment: Using Mediation as a Guide.' September 1, 2012). Available at SSRN: http://ssrn.com/abstract $=2140220$ or http://dx.doi.org/10.2139/ssrn.2140220. Downloaded on $3 / 3 / 13$.

Shepard, M. (1975). Fritr, New York, E.P. Dutton.

Sinclair, M. (2011), 'An integrated framework of intuition', in M Sinclair (ed.), Handbook of intuition research, Edward Elgar, Cheltenham, UK, pp. 3-16.

Staemmler, F. M. (2011). Empathy in Psychotherapy: How Therapists and Clients Understand Each Other, New York, Springer.

The Mediators Institute of Ireland (2011) www.themii.ie.

Winbolt, B. (2014). 'Mindfulness and the Mediator.' The Journal of Mediation and Applied Conflict Analysis.

Accessed from kennedyinstitute.nuim.ie/ content/mindfulness-and-mediator on $20^{\text {th }}$ November 2014.

Wissler, R. (2002). 'Court-Connected Mediation in General Civil Cases: What We Know from Empirical Research.' Obio State Journal of Dispute Resolution, 17, 641-703.

Yontef, G. (1993), 'Awareness, Dialogue, and Process', The Gestalt Journal 2 (1): 27-45.

Delma Sweeney is the Programme Director of Mediation \& Conflict Intervention at the Edward M Kennedy Institute, Maynooth University. As one of the first mediators in Ireland, beginning her practice with the Family Mediation Service in 1986, she has had extensive experience of mediating many forms of dispute. She is accredited as a mediator with the Mediators Institute of Ireland, as a psychotherapist with the Irish Council of Psychotherapy and an accredited trainer with the European Association of Psychotherapy. She is in the final stages of a $\mathrm{PhD}$ researching the use of intuition in mediation practice 